\title{
A methodological approach for manufacturers to enhancevalue-in-use of service-based offerings considering three dimensions of sustainability
}

Tomohiko Sakao, Wasserbaur Raphael and Mathieux Fabrice

The self-archived postprint version of this journal article is available at Linköping University Institutional Repository (DiVA):

http://urn.kb.se/resolve?urn=urn:nbn:se:liu:diva-156668

N.B.: When citing this work, cite the original publication.

Sakao, T., Raphael, W., Fabrice, M., (2019), A methodological approach for manufacturers to enhancevalue-in-use of service-based offerings considering three dimensions of sustainability, CIRP annals, 68(1), . https://doi.org/10.1016/j.cirp.2019.04.084

Original publication available at:

https://doi.org/10.1016/j.cirp.2019.04.084

Copyright: Elsevier

http://www.elsevier.com/

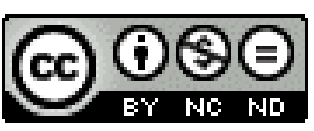




\title{
A methodological approach for manufacturers to enhance value-in-use of service-based offerings considering three dimensions of sustainability
}

\author{
Tomohiko Sakao (2) ${ }^{\mathrm{a},{ }^{*}}$, Raphael Wasserbaur ${ }^{\mathrm{a}}$, Fabrice Mathieux ${ }^{\mathrm{b}}$ \\ a Division of Environmental Technology and Management, Department of Management and Engineering, Linköping University, Linköping, Sweden \\ ${ }^{b}$ European Commission, Joint Research Centre, Ispra, Italy
}

To shift towards a sustainable society, lifecycle engineering methodologies addressing the social dimension need to be advanced. A new methodological approach is proposed for manufacturers to address the three dimensions of sustainability. This approach aims to enhance value-in-use of service-based offerings and supports designers with two social indicators and five generally applicable recommendations involving multiple product lives towards a circular economy. For validation, it was applied to the case of a manufacturer of washing machines for European consumer markets. Results show that the approach supports designers to incorporate the social dimension efficiently while improving resource efficiency.

Service; Environment; Social sustainability

\section{Introduction}

Facing our societies' need to transition towards a circular economy (CE) and a sustainable society at large, manufacturing firms are required to redesign their products' lives by implementing, e.g., remanufacturing. In this context, how to use and manage critical raw materials (CRMs) is an important issue [1]: CRMs for the European Union (EU) are of economic importance and present a high risk of supply disruption. In particular, theory for CE engineering needs to be developed to, e.g., recover residual value of products and components [1].

In addition, modern business practice emphasises the social dimension equally as the environmental one [2]. Regarding social sustainability, Sutherland et al. [2] showed relevant national-level indicators as well as stakeholders and indicators for manufacturers. For the enterprise level, relevant indicators are further developed (e.g. [3]).

For an enterprise's lifecycle engineering practice, few insights are available on how to simultaneously consider the three dimensions of sustainability: economic, environmental, and social [2]. Thus, developing an approach to consider the multiple dimensions of sustainability has been set as a goal of future research [2]. This is the grand challenge tackled by this article.

Service-based offerings by manufacturers, or Product/Service Systems (PSSs), are combined offerings of products and services (a higher-level concept for offerings than products with a focus on value-in-use [4]). PSSs provide a potential for economic and environmental advantage by, e.g., closing the loop. Therefore, this article takes advantage of PSS to tackle this grand challenge. Concretely, it proposes a new approach to enhance value-in-use addressing the three dimensions of sustainability. The approach is applied to the case of a major European home appliance manufacturer to enhance their solutions.

The new contribution of this article is three-fold: 1) a new methodological approach to address the three dimensions of sustainability (mainly the environmental and social); 2) one of the early quantifications of contribution to CRM from the PSS standpoint; and 3) a PSS case in the B2C (business to consumers) markets run by a manufacturer analysed and reported.

\section{State of the art in theory and practice}

Despite many lifecycle engineering methods developed, a systematic methodology to identify and take cross value-chain opportunities for closing the loop is missing [1]. The insight of how to tackle the CRM issue from the lifecycle perspective is also scarce; compare, e.g., the recovery of CRM at the end of life [5].

Research on social sustainability is underdeveloped compared to that on environmental sustainability within engineering, but advanced research [3] reports relevant social entities for a manufacturer; i.e., employees, customers, stockholders/owners, suppliers, the community, and the public. For each entity, a few indicators were developed. The income level is discussed usually for employees but not for customers. In PSS literature, the social aspect has been rarely addressed with the exception of generally pointing out the potential for the creation of more jobs [6].

The practice of PSSs thus far has been reported more from B2B (business to business) contexts, but connectivity through the IoT (Internet of things) has brought new service opportunities to B2C markets [7]. Possibly in relation to this, a new PSS with a timebound subscription for passenger cars named Care by Volvo was launched in 2017, and several types of home appliances will be launched by Panasonic in 2020 (see a study with the company [7]). However, successful PSS offerings by manufacturers on the B2C markets are rarely reported in the literature.

To conclude from the above, more knowledge of theory and practice is needed for a manufacturer to engineer PSS offerings to enhance value-in-use concerning the three dimensions of sustainability. In addition, insights of manufacturers' PSSs launched on a B2C market are lacking in the extant literature.

\section{Methodological approach proposed for a manufacturer}

This approach builds upon a PSS design method that was validated [8] and implemented at complex product manufacturers. It aims to enhance value-in-use for both users and the provider and takes the form of a procedure consisting of eight iterative steps; see Figure 1. Its new elements are focused on below; the elements in the existing method are not explained. 


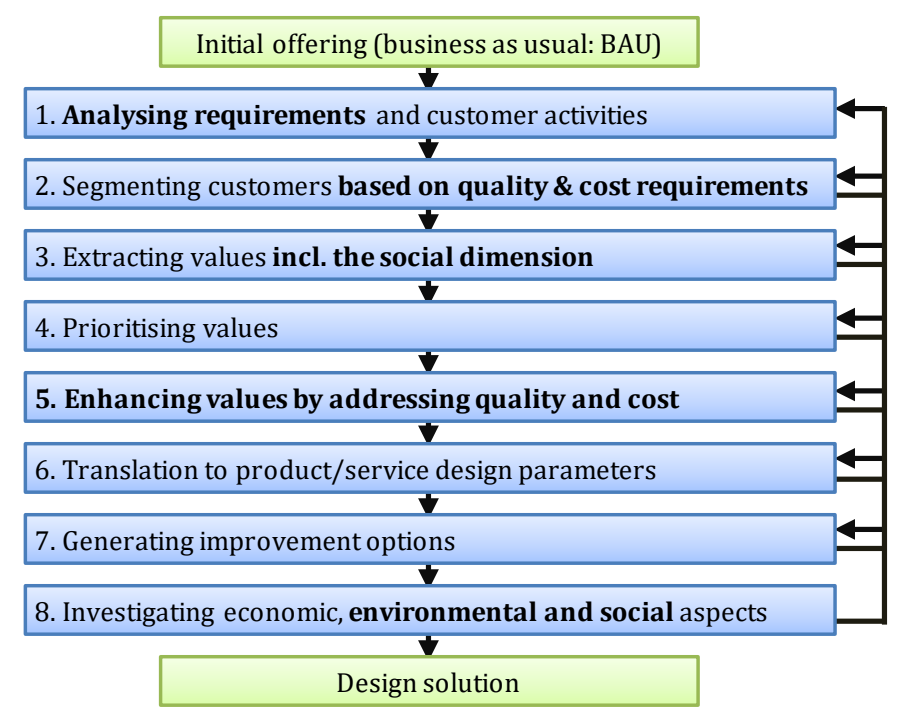

Figure 1. Proposed procedure based on [8] with its new elements in bold.

Step 1: Analysis is carried out not only about target customer activities but also requirements. The requirements from the governmental regulations of relevance to the offering in question are identified and analysed, as they are part of requirements. This is particularly relevant when new business models are explored. The regulations of relevance to PSSs include those about a. o. leasing, warranty, ownership and privacy information. Here, regulations are seen as something that could be changed.

Step 2: In segmenting customers, their requirements on product quality and economic cost to access the offering are used, as they are two major constituents of value-in-use [4].

Step 3: In extracting values, special attention is paid to the social dimension. The indicators developed [3] to help in this are exploited here in the design context. As the recommended social entities of relevance [3] are broad, the customer as the target social entity is the focus here, assuming this is the top priority for an enterprise. For the customers, most relevant indicators seem to be "percentage of company products/services that directly meet the basic needs of the customer" for basic needs (Indicator 1) and "percentage of customers that believe company products/services improve their quality of life" for customer actualization needs (Indicator 2) [3] and, therefore, these are recommended here as criteria for the values. Basic needs referred to by Indicator 1 are given here by part of one of the widely acknowledged definitions [9]: minimum requirements of a family for private consumption food, shelter, and clothing as well as certain household equipment and furniture.

Step 5: This is a newly created step to enhance the value-in-use. The value-in-use is a function of time $t$ (for the product in use) and is decomposed into the product quality from a user's viewpoint $q(t)$ and the user's economic cost to access $c(t)$ using the same parameters as Step 2 (in line with a definition of value as "the quality for the price" [4]). A product may have multiple lives, while the major components of the product are maintained by e.g. reuse and remanufacturing. Each product life (the $k$ th life) is modelled to have its minimum level of quality $\left(\mathrm{qm}_{k}\right)$ and its maximum cost $\left(\mathrm{cm}_{k}\right)$ during its entire period (estimating $\mathrm{qm}_{k}$ and $\mathrm{cm}_{k}$ for a segment is beyond this article). The $q(t)$ decreases (from the initial quality $\mathrm{qi}_{k}$ ) through use over time and its inevitable deterioration, while it is increased by services such as repair. The cost here is determined by the price of the offering (based on the payment model) and that of utilities (e.g., electricity). They evolve over time as exemplified by Figure 2; in this example, a flat-rate cost is given during the first life ( $\left.\mathrm{t}_{0} \leq t \leq \mathrm{t}_{1}, \mathrm{t}_{0}=0\right)$, and investment and service costs are incurred during the second life $\left(\mathrm{t}_{1} \leq t \leq \mathrm{t}_{2}\right)$.

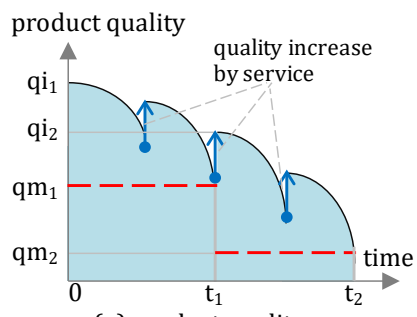

(a) product quality

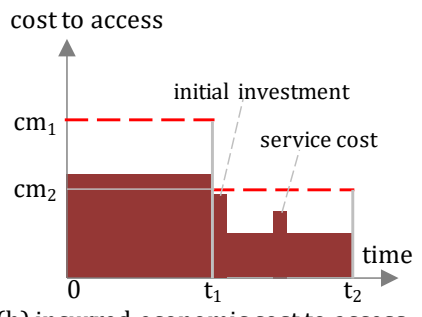

(b) incurred economic cost to access
Figure 2. A schematic presentation of quality and cost for multiple lives.

The task of this step is to find an alternative with $\mathrm{j}$ lives that satisfies the following two constraints for any integer $k(1 \leq k \leq \mathrm{j})$, with the objective to increase the integral of $q(t)$, where $t_{0} \leq t \leq \mathrm{t}_{\mathrm{j}}$ :

$q(t) \geq \mathrm{qm}_{k}$, where $\mathrm{t}_{\mathrm{k}-1} \leq t \leq \mathrm{t}_{\mathrm{k}}$ and

$c(t) \leq \mathrm{cm}_{k}$, where $\mathrm{t}_{\mathrm{k}-1} \leq t \leq \mathrm{t}_{\mathrm{k}}$.

Multiple alternatives may be derived here. To assist in this, the recommendations (Rs) below are presented to the designer. R1, $\mathrm{R} 2, \mathrm{R} 4$, and $\mathrm{R} 5$ are derived from the objective and constraint about the product quality, while R3 originates from the constraint about the cost. These may be combined for an improved offering. R1. Provide services to keep the quality level for a longer time.

R2. Find the $k$ th life with $\mathrm{qm}_{k}$ below $\mathrm{qm}_{k-1}$ for a longer total time.

R3. Keep product ownership to apply a flat-rate cost below $\mathrm{cm}_{k}$.

R4. Increase $\mathrm{d} q(t) / \mathrm{d} t$ to keep the quality level for a longer time.

$\mathrm{R} 5$. Increase qi ${ }_{1}$ to raise the quality for a longer time.

Step 8: For the economic aspect, the total cost for the $\mathrm{j}$ lives as well as the total revenue for the provider (a part of the integral of $c(t)$, where $t_{0} \leq t \leq \mathrm{t}_{\mathrm{j}}$ ) may be assessed. For the social dimension, the two criteria brought in Step 3 (i.e., Indicators 1 and 2) are used here. For the environment, life cycle assessment (LCA) or material flow analysis (MFA) may be used. After the assessment with these multiple criteria, a design solution is selected.

\section{Application of the approach to real B2C case}

\subsection{The European manufacturer and its real B2C case}

The company is an original equipment manufacturer (OEM) of high-quality washing machines. As business as usual (BAU), the OEM sells products including a standard warranty. The company has interest and ambitions to collaborate with other actors (e.g., in the reverse supply chain) in order to close the loop. Trials were conducted with recyclers to feed components back to the firm. The OEM sees business opportunities with environmental and social sustainability issues, in particular through CE strategies.

Only recently, the manufacturer has launched a PSS offering where customers lease washing machines for a maximum term of six years. This offering is now available only to the Dutch market. This type of offering is not novel to the Dutch market (e.g., www.homiepayperuse.com), but that by an OEM controling the product design is rare. This OEM sees potential to improve their offerings from different aspects including the environmental and social, partly based on the apparent popularity of these new PSSs. Thus, the approach was, in collaboration with an expert panel of the manufacturer, applied to the case of providing washing machines in the EU and then evaluated. The panel consisted of four key managers on sustainability, business development, marketing, and research and development.

\subsection{Results from applying the approach to the case}

Step 1: Analysis was carried out about activities of washing clothes, but here only the finding from relevant governmental regulations about leasing is described. It was found that a leasing period of a product in the Netherlands as of now must be shorter 
than $75 \%$ of the product lifetime, which is set at eight years for a washing machine: this results in a six-year maximum lease-term.

Step 2: Concerning the economic cost, a significant number of low-income customers were found to suffer from energy poverty, defined as a situation of not being able to adequately get heat or energy services in homes at an affordable cost [10]; in Belgium and the UK, e.g., $20-30 \%$ of the population is at risk of energy poverty [10]. Another segment is expected to have higher requirements on product quality and even was shown to have the willingness to pay for a PSS contract [11].

Step 3: Concerning the social dimension, a washing machine was confirmed relevant to Indicators 1 and 2 (see Step 3 in Section 3), as it contributes to clothing and is household equipment keeping the clothes clean.

Step 4: This step is omitted due to the space limitation.

Step 5: The following alternatives (As) were derived by applying the five recommendations to improve the BAU. A1: applying R1 and R3 resulted in providing a washing machine with services with a flat rate to low-income people, e.g., in Belgium (see Step 2 above). A2: R1, R2 and R3 - providing a PSS contract for six years and then, after remanufacturing, selling a machine with a decreased price to a different segment (two lives). A3: R1 and R3 with a hypothetical regulation - considering a scenario that the regulation for the leasing duration in the Dutch market (see Step 1 above) be abolished.

Step 6: The durability as a critical design parameter was investigated on a product component level. According to statistics about washing machines in the EU [12], electronic parts cause the highest portion (ca. 40\%) of unrepaired cases within a single failure mode, which is followed by shock absorbers and bearings with ca. $15 \%$ in total. For the service aspect, e.g., the multiple lives by the manufacturer in $\mathrm{A} 2$ entailed a need of taking back products with remanufacturing and recommissioning.

Step 7: Considering the durability, the electronic components were decided to be replaced in the services. Further, the broken shock absorbers and bearings were proposed to be salvaged through redesigning the product structure for easier access.

Step 5: Returning to Step 5, obtained was A4: R1, R3 and R4 - a PSS with the redesigned product structure in particular for an easier repair and thus a longer product lifetime was proposed.

Step 8: In total, four new alternatives were input: $A 1$ and $A 2$ are partly launched on the markets. These four As and the BAU were assessed after concretizing some aspects through consultation with experts of the manufacturer, as summarized in Table 1: e.g., the length of use when owned by an end user is estimated at 11.7 years using Dutch data [13] in A0 and A2. The assumption for the use length in $\mathrm{A} 1$ and $\mathrm{A} 3$ is 18 years, involving remanufacturing once. The use length of A4 is assumed to be longer than A3 by $5 \%$. A1 adopts a special social organization as a service provider between the manufacturer and low-income customers.

Table 1

Summary of the BAU (A0) and the four alternatives assessed.

\begin{tabular}{l|lllll}
\hline$\#$ & Contracts & $\begin{array}{l}\text { Launched } \\
\text { market }\end{array}$ & $\begin{array}{l}\text { Use } \\
\text { length }\end{array}$ & $\begin{array}{l}\text { Product } \\
\text { design }\end{array}$ & Maintenance \\
\hline A0 & Product & Dutch & 11.7 & As is & End user \\
A1 & PSS & Belgian & 18 & As is & Mfr. \\
A2 & PSS, Product & Dutch & 17.7 & As is & Mfr., End user \\
A3 & PSS & Not yet & 18 & As is & Mfr. \\
A4 & PSS & Not yet & 18.9 & Adapted & Mfr. \\
\hline
\end{tabular}

Note: The unit for the use length is a year. Mfr. stands for manufacturer.

Below, the environmental aspect is the focus. Static MFA is adopted to show basic indicators on resource efficiency. The functional unit can be regarded as one-washing-cycle usage of a washing machine. The BOM (bill of materials) of the BAU model was used. Only the results regarding antimony ( $\mathrm{Sb})$, bismuth (Bi), beryllium (Be), cobalt (Co), aluminium ( $\mathrm{Al}$ ), and copper $(\mathrm{Cu})$ are shown here. The first four materials are from printed circuit boards and CRMs for the EU. The last two are also extremely important for the EU manufacturing industry and represent a high share of a washing machine. The data used for collection and recycling are published in the supplementary material.

How the outflow of each material is relatively changed in an alternative compared to A0 is shown in Figure 3. The system boundary includes use, remanufacturing and recycle. The results of $\mathrm{A} 1$ and $\mathrm{A} 3$ are identical. $\mathrm{Sb}, \mathrm{Be}$ and $\mathrm{Al}$ share their result with $\mathrm{Bi}$, $\mathrm{Co}$ and $\mathrm{Cu}$, respectively, due to no difference in the used data about their collection and recycling. Regarding the total, A1-A4 are superior to the BAU by a gap of between $27 \%$ and $38 \%$. This is mainly caused by the longer use slowing down the outflow. Further, $\mathrm{Al}$ and $\mathrm{Cu}$, which are unused in electronic parts, are better (35-38\%) than the others (27-32\%), which are input additionally due to the replacement of the electronic parts in the services. The ratios of the recycled materials in all alternatives are identical for $\mathrm{Al}$ and $\mathrm{Cu}(96 \%)$ as well as Be and $\mathrm{Co}(0 \%)$. For $\mathrm{Sb}$ and $\mathrm{Bi}$, those in $\mathrm{A} 1, \mathrm{~A} 3$, and $\mathrm{A} 4$ are $80 \%$ and higher than in $\mathrm{A} 0$ and A2 (23\%) owing to the higher ratios of PSS' collection to official recycling schemes with the higher yield ratio.

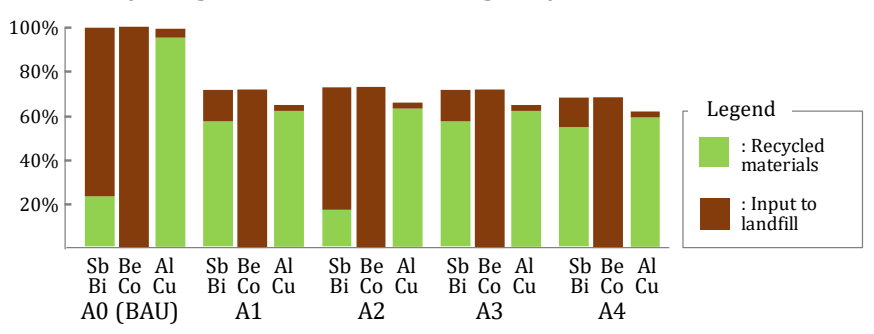

Figure 3. Comparison of outflows per washing cycle divided into the recycled materials and the input to landfill.

\section{Discussion}

\subsection{Evaluation of the proposed approach}

The approach in Section 3 was shown to be adequate in the industrial setting through application to the case in Section 4: addressing the regulations as well as using the two social indicators and the five recommendations were useful to arrive at the improved design solutions. According to an expert of the OEM, a procedure with these insights appears novel in the company and the obtained solutions are sensible. Further, the advantage of this procedure is to be able to guide manufacturers' processes to identify improvement opportunities by broadening their design space yet limiting to relevant aspects such as social aspects and regulations. This broadened space is missing in existing approaches to PSS design in the literature. In particular, focusing on a few carefully nominated social indicators contributed positively to address the vast space of social sustainability efficiently.

The five recommendations each may appear obvious but are valuable due to the comprehensiveness as a set from engineers' viewpoints. Further, the function used as a basis for the recommendations, i.e., an integral of quality over time, is found useful. Different functions exist to formulate value: e.g., value is an integral of consumer satisfaction over time [14], which is influenced by product quality and other factors pertaining to individuals such as their expectation. An advantage of the used function is its reduced complexity, as those factors are considered constant for simplicity. Still, the function is rich enough to make the recommendations sensible. $\mathrm{R} 5$ was not used in this case but concerns product design with sufficient insights in literature.

The information required for the procedure partly exists in sectors other than manufacturing. In using this approach, a 
manufacturer may need to collect information additionally compared to traditional product development. However, such effort is needed to reach innovation leading to a higher impact.

This improvement approach is applicable to a broad range of products, not only other types of home appliances but also, e.g., batteries. Battery business is growing, and thus governments express interest in investigating the (non-)fitness of related existing regulations [15], increasing the relevance even more.

\subsection{Implications for the environmental and social aspects}

The MFA showed that service-based models with closed loops substantially improve the BAU in terms of resource efficiency mainly through a longer use length and increased collection ratios. The latter essentially enables better control of the product lives by OEMs and thus that of (critical) raw materials. Other positive impacts on the environment are expected: e.g., reduced energy use from the use phase thanks to more energy-efficient machines used by low-income users that cannot afford to buy and own such machines with a high sales price. This also leads to a reduction in $\mathrm{CO}_{2}$ emissions from the lifecycle perspective.

The collection rates differ between countries, and thus caution should be paid to this uncertainty. The reality is also dynamic, and the market size of PSSs for washing machines is expected to grow. This dynamic is of high relevance to the resource issue. Nonetheless, this reported case is an early contribution to CRM efficiency by PSSs based on real initiatives in industry.

A2 with the second life of high-quality products with an affordable price provides additional opportunities to a pricesensitive segment. A1 enables low-income people to use highquality machines without high up-front investment. Also, A3 and A4 involve new services for clothing. Thus, the four alternatives are regarded as positively influential to Indicators 1 and 2 on the social aspect. Further, A1 meets the sustainable development goal 10 by United Nations, i.e., to reduce inequality within and among countries. These offerings are enabled only by deliberate lifecycle design for different segments and may be regarded as reference models addressing the three dimensions of sustainability. How the social aspect is interpreted and incorporated in this approach might be simplistic (e.g. job creation by remanufacturing is entailed in the case but not explicitly addressed by the approach). However, it is of high value to practitioners because of little insight available for this issue.

\subsection{Implications to manufacturers' practice}

The economic dimension is crucial (Step 8 includes the economic aspect such as investment in remanufacturing) but could not be explained fully due to the space limitation; see [16] for a positive contribution to the economic dimension by PSS. Concerning the regulations addressed as part of the design space in the proposed approach, they are obviously not under control of one enterprise or even one industry organization; however, the impact brought by a changed regulation cannot be underestimated for innovation.

\section{Conclusion}

This article proposed an approach to assist manufacturers to design multiple lives of a product for sustainability, in particular, contributing to how to incorporate the social dimension. The application at a leading manufacturer in Europe succeeded in generating new solutions with potential positive contribution to CRM efficiency. Further, insights about a manufacturer's PSSs on the $\mathrm{B} 2 \mathrm{C}$ markets, e.g., regarding remanufacturing and product design are reported. Future work includes the application to other products and addressing the scope of entities broader than the customers on the social context.

\section{Acknowledgements}

This research was supported by an expert contract by the European Commission (CT-EX2014D222360-101). The authors would like to thank the manufacturer, who provided invaluable support and data related to their business cases.

\section{Disclaimer}

The views expressed in the article are personal and do not necessarily reflect an official position of the European Commission. Neither the European Union institutions and bodies nor any person acting on their behalf may be held responsible for the use which may be made of the information contained therein.

\section{References}

[1] Tolio, T., A. Bernard, M. Colledani, S. Kara, G. Seliger, J. Duflou, O. Battaia, and S. Takata, Design, management and control of demanufacturing and remanufacturing systems. CIRP Annals Manufacturing Technology, 2017. 66(2): p. 585-609.

[2] Sutherland, J.W., J.S. Richter, M.J. Hutchins, D. Dornfeld, R. Dzombak, J. Mangold, S. Robinson, M.Z. Hauschild, A. Bonou, P. Schönsleben, and F. Friemann, The role of manufacturing in affecting the social dimension of sustainability. CIRP Annals - Manufacturing Technology, 2016. 65(2): p. 689-712.

[3] Hutchins, M.J., J.S. Richter, M.L. Henry, and J.W. Sutherland, Development of indicators for the social dimension of sustainability in a U.S. business context. Journal of Cleaner Production, 2018.

[4] Zeithaml, V.A., Consumer Perceptions of Price, Quality, and Value: A Means-End Model and Synthesis of Evidence. Journal of Marketing, 1988. 52(July): p. 2-22.

[5] Ueberschaar, M., S.J. Otto, and V.S. Rotter, Challenges for critical raw material recovery from WEEE - The case study of gallium. Waste Management, 2017. 60: p. 534-545.

[6] Beuren, F.H., M.G.G. Ferreira, and P.A.C. Miguel, Product-service systems: a literature review on integrated products and services. Journal of Cleaner Production, 2013. 47: p. 222-231.

[7] Takenaka, T., Y. Yamamoto, K. Fukuda, A. Kimura, and K. Ueda, Enhancing products and services using smart appliance networks. CIRP Annals - Manufacturing Technology, 2016. 65(1): p. 397-400.

[8] Sakao, T., H. Birkhofer, V. Panshef, and E. Dörsam, An Effective and Efficient Method to Design Services: Empirical Study for Services by an Investment-machine Manufacturer. International Journal of Internet Manufacturing and Services, 2009. 2(1): p. 95-110.

[9] ILO, Employment, Growth and Basic Needs: a One World Problem. 1978, Geneva: International Labor Organization.

[10] Pye, S., A. Dobbins, C. Baffert, J. Brajković, R. De Miglio, and P. Deane, Energy poverty and vulnerable consumers in the energy sector across the EU: analysis of policies and measures. 2015, INSIGHT_E project funded by the EC 7th Framework Programme.

[11] Lieder, M., F.M. Asif, A. Rashid, A. Mihelič, and S. Kotnik, A conjoint analysis of circular economy value propositions for consumers: Using "washing machines in Stockholm" as a case study. Journal of Cleaner Production, 2018. 172: p. 264-273.

[12] Tecchio, P., F. Ardente, and F. Mathieux, Analysis of durability, reusability and reparability - Application to washing machines and dishwashers. JRC Technical Report, 2016. p. 129.

[13] Wang, F., J. Huisman, A. Stevels, and C.P. Baldé, Enhancing E-waste estimates: improving data quality by multivariate input-output analysis. Waste Management, 2013. 33(11): p. 2397-2407.

[14] Kumar, V., P.S. Shirodkar, J.A. Camelio, and J.W. Sutherland, Value flow characterization during product lifecycle to assist in recovery decisions. International Journal of Production Research, 2007. 45(1819): p. 4555-4572.

[15] EC, Europe on the move - Sustainable Mobility for Europe: safe, connected and clean: Annex 2. 2018: Brussels. p. 10.

[16] Sakao, T. and M. Lindahl, A method to improve integrated product service offerings based on life cycle costing. CIRP Annals Manufacturing Technology, 2015. 64(1): p. 33-36. 


\section{Data on collection and recycling rates for materials for the considered scenarios}

For the MFA calculations presented in the article, data for each material from the BOM was multiplied by recycling rates of each material, which depend both on the collection rates of the product flows and on the yield of the recycling processes. The outcomes were then divided by the number of washing cycles for the scenarios. See the system boundary in Figure S1.

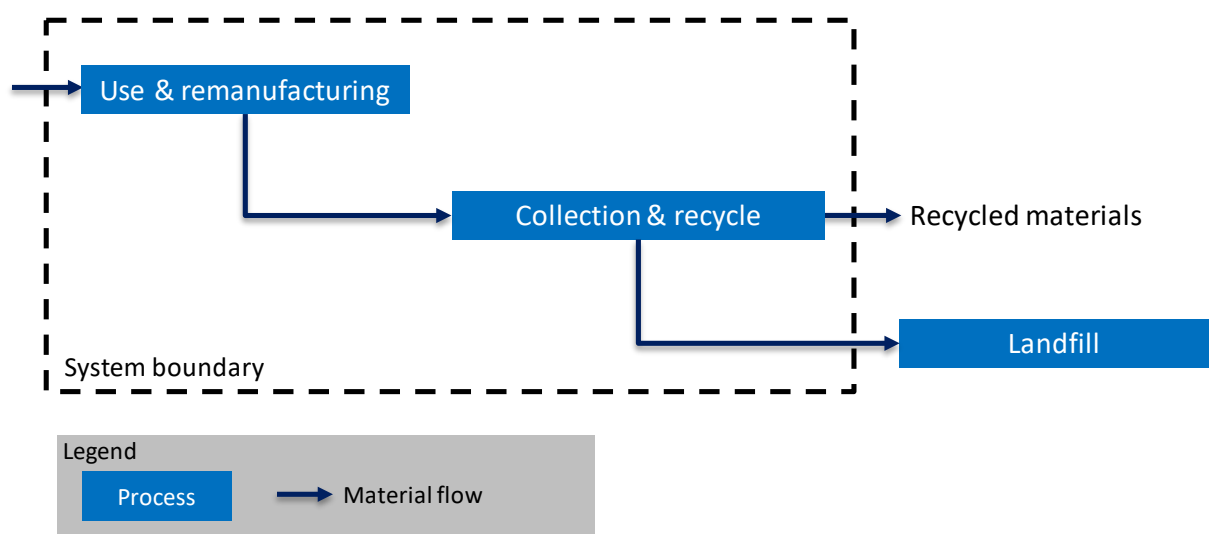

Figure S1. Conceptual diagram used for MFA.

For the "product" case (A0 and A2), at the end-of-life, washing machines are assumed to be absorbed by WEEE flows (data referring to the Netherlands) that are actually either collected and treated by official schemes ( $29 \%$ of the flow), treated by non-official schemes (i.e. mainly treated in shredders) (44\%), not documented (23\%), i.e. probably exported or treated by shredders, or exported $(4 \%)^{1}$. For such flows, only for official schemes ( $29 \%$ of the flows only), it can be assumed that washing machines are properly treated following a depollution phase where printed circuit boards can be extracted. In the other cases, printed circuit boards (Containing Bi, Sb, Be and $\mathrm{Co}$ ) are assumed to not be extracted before shredding.

For the "PSS" case (A1, A3 and A4), at the end-of-life, it is assumed that the manufacturer collects $100 \%$ of the washing machines and channels them to operators that implement a depollution phase where printed circuit boards are extracted.

These statistics and assumptions lead to the recycling rates (shown in Bold) for the 6 materials under the study presented in Table S1.

\footnotetext{
${ }^{1}$ Huisman, J., van der Maesen, M., Eijsbouts, R.J.J., Wang, F., Baldé, C.P., Wielenga, C.A., (2012), The Dutch WEEE Flows. United Nations University, ISP - SCYCLE, Bonn, Germany, March 15, 2012 http://www. weeeforum.org/news/the-dutch-weee-flows
} 
Table S1. Recycling rates for materials for considered scenarios.

\begin{tabular}{|c|c|c|c|c|c|c|c|c|}
\hline \multicolumn{2}{|l|}{ Scenarios } & $\begin{array}{l}\text { Collection } \\
\text { rate for } \\
\text { products }\end{array}$ & $\begin{array}{l}\text { Recovery } \\
\text { yield for } \\
\mathrm{Al} \text { and } \\
\mathrm{Cu}^{2}\end{array}$ & $\begin{array}{l}\text { Recycling } \\
\text { Rate for } \\
\mathrm{Al} \text { and } \\
\mathrm{Cu}\end{array}$ & $\begin{array}{l}\text { Recovery } \\
\text { yield for } \\
\mathrm{Sb} \text { and } \\
\mathrm{Bi}^{3}\end{array}$ & $\begin{array}{l}\text { Recycling } \\
\text { Rate for } \\
\mathrm{Sb} \text { and } \mathrm{Bi}\end{array}$ & $\begin{array}{l}\text { Recovery } \\
\text { yield for } \\
\mathrm{Be} \text { and } \\
\mathrm{Co}^{3}\end{array}$ & $\begin{array}{l}\text { Recycling } \\
\text { Rate for } \\
\text { Be and } \\
\text { Co }\end{array}$ \\
\hline \multicolumn{2}{|l|}{ "PSS" Case } & $100 \%$ & $96 \%$ & $96 \%$ & $80 \%$ & $80 \%$ & $0 \%$ & $0 \%$ \\
\hline \multirow{3}{*}{$\begin{array}{l}\text { "Product" } \\
\text { Case }\end{array}$} & $\begin{array}{l}\text { Official } \\
\text { Scheme }\end{array}$ & $29 \%$ & $96 \%$ & & $80 \%$ & & $0 \%$ & \\
\hline & $\begin{array}{l}\text { Non-official } \\
\text { scheme (e.g. } \\
\text { shredders, } \\
\text { export, not } \\
\text { documented) }\end{array}$ & $71 \%$ & $96 \%$ & & $0 \%$ & & $0 \%$ & \\
\hline & $\begin{array}{l}\text { Weighted } \\
\text { average }\end{array}$ & & & $96 \%$ & & $23 \%$ & & $0 \%$ \\
\hline
\end{tabular}

\footnotetext{
2 JRC report, 2016. Feasibility Study for Setting-up Reference Values to Support the Calculation of Recyclability / Recoverability Rates of Electr(on)ic Products, p. 68.

3 JRC report, 2016. Feasibility Study for Setting-up Reference Values to Support the Calculation of Recyclability / Recoverability Rates of Electr(on)ic Products, p. 70-71.
} 